\title{
LOS INFIERNOS DE LO ABSTRACTO (KAFKA EN ZAMBRANO)
}

\section{THE HELLS OF THE ABSTRACT (KAFKA IN ZAMBRANO)}

\author{
Virginia TRUEBA MirA* \\ Universitat de Barcelona
}

Resumen: Este trabajo analiza los textos que María Zambrano publicó sobre Franz Kafka atendiendo a las tres dimensiones que, a juicio de la pensadora, merecen destacarse de la obra del escritor: la narrativa, la histórica y, especialmente, la testimonial. En este último sentido, Zambrano ve desplegada en Kafka una crítica radical al pensamiento moderno y, en concreto, a la conciencia cartesiana, cuya materialización (monstruosa e irrepresentable) encarnarían a su juicio los diversos personajes de sus narraciones. El concepto de vida larvaria y de vida larvada que Zambrano desarrolla en relación a esta última cuestión constituyen el centro de sus análisis, de los que se desprende, a su vez, un diagnóstico pesimista (Zambrano habla en términos de infierno) del mundo contemporáneo.

Palabras Clave: María Zambrano, Franz Kafka, pensamiento español contemporáneo, novela contemporánea, crisis de la modernidad.

Aвstract: This essay analyzes the texts that Maria Zambrano wrote about Franz Kafka in the three dimensions that, in her opinion, deserve to be emphasized in the work of the novelist: the narrative, the historical and, especially, the testimonial aspect. In the latter sense, Zambrano sees in Kafka a radical critique of modern thought and, in particular, Cartesian consciousness, whose materialization (monstrous and unrepresentable) would be embodied in the various characters of the novelist. The concepts of larval life and larvae life that Zambrano develops in relation to this last issue constitute

* Profesora Titular de Universidad, Facultat de Filologia, Gran Via de les Corts Catalanes 585, 08007 Barcelona, trueba@ub.edu 
the center of her analysis which, in turn, emits a pessimistic diagnosis (Zambrano speaks in terms of hell) of the contemporary world.

KeYwords: María Zambrano, Franz Kafka, contemporary Spanish thought, contemporary novel, crisis of modernity.

\section{Introducción}

Zambrano escribió sobre Kafka en tres ocasiones, 1941, 1947 y 1965. Se trata de trabajos importantes, de cierta extensión y centrados todos ellos en $\mathrm{La}$ metamorfosis, El proceso y El castillo ${ }^{1}$. Lo que me propongo en este trabajo es intentar responder a la pregunta de por qué, de entre todos los novelistas modernos ${ }^{2}$, Kafka ocupa en las reflexiones de Zambrano un lugar privilegiado. Se dirá que Kafka ocupa con frecuencia ese lugar en el pensamiento contemporáneo, y es cierto. La cuestión es analizar entonces los motivos en cada caso, más allá de lo obvio.

Como punto de partida, me parece interesante recordar lo que afirmaba Jorge Semprún en La escritura o la vida (1994) al constatar que la experiencia de los campos de concentración y de exterminio carecía de una "tradición referencial de mitos o de alegorías históricas que habrían facilitado su representación” (Semprún, 1995: 198). Pues bien, creo que éste es precisamente uno de los motivos, y no menor, de la proximidad de Zambrano a Kafka o, dicho de otro modo, lo que Zambrano ha encontrado en la obra de Kafka es una actualización de la vieja fábula aristotélica (Zambrano, 2001: 131), de aquella ficción bien articulada capaz de contar una determinada verdad, en este caso la verdad del mundo moderno, cuya lógica, entiende también Zambrano en consonancia con otros pensadores contemporáneos -entre ellos algunos de los integrantes de la Escuela de Frankfurt y, más tarde, autores como Giorgio Agamben o Zygmunt Bauman-, halla expresión definitiva en la realidad de los campos, una lógica que para ella venía, no obstante, articulándose mucho antes y que seguiría viva después.

\footnotetext{
${ }^{1}$ Las referencias son las siguientes: "Franz Kafka, mártir de la miseria humana" (Espuela de Plata, La Habana, agosto de 1941), "Franz Kafka, un mártir de la lucidez" (Asomante, Puerto Rico, 1, enero-marzo, 1947), "La novela-tragedia: El castillo, de Kafka" (El sueño creador, 1965).

${ }^{2}$ No puedo entrar aquí en la cuestión de si los textos de Kafka son novelas o narraciones. Ha trabajado en esta línea, y a su estudio me remito, Laura Llevadot desde el pensamiento de la novela de Adorno y Benjamin en su relación con el de Zambrano (2010).
} 
En esta defensa de la fábula -de la inventio- por parte de Zambrano está contenida una idea importante, recurrente en todo su pensamiento, y es la de que la vida necesita para ser expresada de una "forma" y una "figura", como dice en 1947 (2001: 131), de un rostro si se quiere, para, entre otras cosas, poder tratar con ella. Esta es precisamente la función de la literatura, el arte o la religión -lo que Zambrano acaba llamando de modo general Poesía-: la función, no de reproducir lo visible sino de hacer visible, de dar a ver ${ }^{3}$. Y en este sentido, en el terreno propio de la narración y frente a otros modos de escritura contemporáneos más disolutivos, la construcción de la fábula sigue siendo para Zambrano la única posibilidad de encontrarle ese rostro a la vida, en el sentido de hacerla visible y en tanto visible, tratable.

Es la misma Zambrano la que se refiere a esos otros modos de escritura contemporáneos y, en concreto, a James Joyce, cuya obra es para ella paradigmática, y ya no solo por el empleo del monólogo interior, incapaz para Zambrano de hacerse cargo de la vida actual, como considera también que ocurre con ciertas formas de deshumanización o desacralización del arte. Joyce es un autor que sí ha recurrido a la fábula en una obra como Ulises, pero lo ha hecho de modo mimético, entiende Zambrano, esa fábula estaba ya inventada y expresaba, además, otro mundo. En realidad, la escritura de Joyce no hace visible el mundo contemporáneo ni ningún otro sino que se hace visible a sí misma. Frente a Joyce, el valor de Kafka estriba para Zambrano en haber sido capaz de inventar la fábula de su propio tiempo, de ahí que le denomine en el

\footnotetext{
${ }^{3}$ Es un dar a ver que tendrá mucha relación con la visibilidad de los sueños, de las aguas, como ha estudiado Carmen Pardo (2003: 100). En el ámbito de la recepción temprana e hispánica de Kafka, el ensayista argentino, Ezequiel Martínez Estrada, afirmará en un trabajo de 1950 que el mundo de Kafka es el real, pero que precisamente por ello solo puede ser expresado "por el mito, por la metáfora, por el lenguaje de la intuición que hablamos cuando estamos dormidos, es decir, cuando nos reintegramos al sentido nocturno y orgánico de la vida" (Martínez Estrada, 2013: 181). Y añade un poco más adelante: "lo que debiera examinarse, pues, es hasta qué punto lo que hemos llamado 'modo mítico de pensar' y 'modo mítico de expresarse' corresponden a un orden efectivo de la realidad. De ser así, toda versión literal y directa debiera desdeñarse como un cuento de hadas". No se olvide que por esos ańos Zambrano está articulando su pensamiento en torno a la relación entre la creación y el sueño como camino de conocimiento, lejos de cierta racionalidad moderna, lejos de la reflexión de Descartes en su Discurso del método cuando escribe lo siguiente: "nos dice la razón que, no pudiendo ser verdaderos nuestros pensamientos, porque no somos totalmente perfectos, deberá infaliblemente hallarse la verdad más bien en los que pensemos estando despiertos que en los que tengamos en sueños" (Descartes, 2011: 128).
} 
texto de 1947 "clásico moderno" (2001: 132) $)^{4}$, lo mismo que, en una dirección similar, le considere verdadero "cronista" de su época (2001: 130), en este caso frente, ya no a los que escriben disolviendo la realidad al estilo de Joyce sino a aquellos que pretenden transmitirla fielmente basándose en datos objetivos.

Fue Jorge Semprún el que afirmó, asimismo, y en este último sentido, su incapacidad de reconocerse en las imágenes que los periodistas americanos filmaron de los campos el primer día de la liberación, ya que "no expresaban nada preciso sobre la realidad mostrada”, escribió (Semprún, 1995: 218). Y es que no se trataba de mostrar la realidad de los campos, sino su lógica, una cuestión, como diría por su parte Walter Benjamin en su trabajo sobre el arte de narrar, de "amplitud de vibraciones" (Benjamin, 1973: 309). Hay también en este aspecto en Zambrano una filosofía de la historia tan opuesta al historicismo positivista y a su metafísica implícita, heredada por cierto periodismo al identificar el dato con la verdad, como cercana a autores como Michel Foucault, Paul Veyne, Michel de Certeau o Hayden White, quienes no han dejado de afirmar que el pasado es siempre diegético, que se construye en la escritura, y que la historia no es algo sucesivo, lineal, en progreso, sino que se forja en el conflicto y en la quiebra, en una dialéctica que no se resuelve nunca y que, por ello mismo, tal vez podría denominarse, en sentido laxo, negativa. Lo que subyace aquí es, por otra parte, un pensamiento de signo ético, muy marcado en Zambrano, donde el sufrimiento de las víctimas no puede ser nunca un accidente inevitable en el camino del progreso histórico (Zambrano, 2001: 125).

Hasta aquí, y muy rápidamente, el marco general desde el que pueden leerse los textos de Zambrano sobre Kafka. Esos textos, no obstante, hilan fino y, aún desde la deuda con el concreto clima existencialista de los años en que se escriben (observable, por ejemplo, en el empleo de un léxico que apunta al mundo de la náusea, de la podredumbre, etc.), tejen una reflexión sobre el siglo XX que, a mi juicio, sigue interpelándonos de un modo interesante.

Junto a la palabra "fábula" o "crónica", Zambrano utiliza la palabra "testimonio" para referirse a la obra de Kafka. De un "doble testimonio", habla Zambrano para ser más precisos. Ahora bien, ¿qué es exactamente eso que la

\footnotetext{
${ }^{4}$ Este de la invención es, mayor si cabe en un mundo donde la imaginación, como afirmó Samuel Beckett, está muerta - de lo que Beckett derivaba el único imperativo eficaz: imagina-. En 1944 el mismo Martínez Estrada reconocerá también en Kafka la "palabra que vuelve a crear mitos y símbolos" por lo que al leer a Kafka se sabe que "estamos leyendo un capítulo de la historia nunca escrita del hombre" (2013: 117).
} 
escritura de Kafka testimonia? Dos cosas, dice Zambrano en el texto de 1941, que son en realidad la misma: la "objetividad" y "la materia". Vamos a ver qué quiere decir Zambrano con ello.

\section{EI testimonio de la objetividad}

Empecemos por la primera cuestión, la objetividad, tal vez la menos sorprendente en el conjunto de la bibliografía sobre Kafka. Se trata, como no es difícil adivinar, de la objetividad como fundamento y finalidad de esa racionalidad moderna que ha hecho acto de presencia en el siglo XVII.

Por una parte, hay que hablar de una racionalidad se ha construido a sí misma como objetiva en el momento en que ha eliminado de sí toda huella de ambivalencia o ambigüedad que pueda contradecirla (Zambrano, 2001: 124). Al mismo tiempo, esa racionalidad persigue descubrir la objetividad, no del ser del mundo -que en parte ha dejado de interesar- sino de su funcionamiento, el cual no podrá estar en desacuerdo, sería absurdo, con esa racionalidad, de tal modo que el instrumento de conocimiento es aquí el que da lugar al objeto de conocimiento. Así por lo menos lo entiende Zambrano en consonancia con tantos otros críticos de la modernidad. Quizás este fuera el motivo de que Heidegger, uno de esos críticos, dijera que la ciencia, paradigma en parte de esa racionalidad, no piensa porque, en realidad, encuentra en el mundo lo que previamente ya ha puesto en el mundo. La cuestión es que, como sabemos, el mundo deja de ser a partir del siglo XVII el organismo que ha sido hasta el momento para pasar a ser un mecanismo. O dicho con la metáfora clásica, el mundo deja de ser un libro y deja de leerse como un libro (lo que hace aún don Quijote) para pasar a ser una máquina, cuyo funcionamiento será desvelado poco a poco por la razón -mecanismo también- ${ }^{5}$. Todo ello es lo que Max Weber llamaría más tarde el desencantamiento del mundo.

Si, como dijera el narrador de La hora de la estrella (1977) de Clarice Lispector, existir no es lógico, la racionalidad moderna hace todo lo posible por demostrar lo contrario. La objetividad en que se funda y que persigue busca sellar el abismo de esa falta de lógica, salvar al hombre de caer por ese agujero que el XVII abrió para los siglos posteriores (ese cielo azul que ni es cielo ni es azul) y por el que sí se adentró, más osada, la literatura. Gracias a esa racionalidad el suelo es ahora firme y sustenta al hombre. Solo que ya no es distinto en cada caso sino el mismo

\footnotetext{
${ }^{5}$ Ver Hans Blumenberg, Paradigmas para una metaforología (2003), a quien cita Cirilo Flórez en una precisa introducción a Descartes (2011), que me ha servido de marco para esta reflexión sobre el origen de la racionalidad moderna.
} 
para todos (uni-forme), y solo que ya no es transitable con los sentidos, siempre engañosos, sino con la razón. El mundo queda, así, sustraído de su singularidad, queda abstraído y transformado en algo que siempre va a resultar racionalizable, o sea, mensurable, cifrable, censable y legislable -controlable en última instancia-.

Si hablamos del mundo como algo legislable nos situamos ya ante la ley de Kafka, esa que no se ve pero que toca todo el rato a sus personajes, la ley invisible pero omnipresente e insobornable. La ley que debe obedecerse para tener el primer derecho de todos: el derecho a existir. La proximidad entre la filosofía moderna y el estado moderno de derecho ha sido analizada, entre otros, por Zygmunt Bauman en un libro temprano, Modernidad y ambivalencia (1991), cuyas tesis Zambrano hubiera compartido con probabilidad, muy en especial la que habla de que la ley del estado moderno enmascara, en realidad, una voluntad de dominio. Para Zambrano, la razón moderna no deviene sino que nace directamente como razón instrumental al servicio del poder. Es lo que para ella Kafka viene a testimoniar, las consecuencias de la "máquina infernal de la justicia", como dice en su texto de 1941 (2013: 108).

\section{EI testimonio de la concreción de la materia}

Ahora bien, hasta aquí el análisis de Zambrano presenta pocas novedades en el conjunto de la bibliografía sobre Kafka. Sí me parecen más destacables sus reflexiones acerca de esa otra parte del testimonio que, a su juicio, Kafka aporta: el testimonio de la materia, de la concreción de la materia para ser más precisos, expresión que voy a intentar explicar a continuación ya que esa materia tiene poco que ver con la de esa metafísica matérica con la que identificamos habitualmente el pensamiento de Zambrano. Son dos materias muy distintas. ¿̇A qué se refiere, pues, Zambrano, cuando habla de la materia en los textos sobre Kafka?, ¿qué materia es esa?

Ahora ya no se trata de que el mundo se haya transformado en cifra sino de que el sujeto, el que ha llevado a cabo esta operación, se ha transformado en larva. La materia a la que se refiere Zambrano es esta, la de la larva. Aquí el foco se desplaza, y en ello consiste el "doble testimonio" de Kafka, del mundo, de sus superestructuras sociales, al sujeto, a la subjetividad del individuo. El sujeto que configuró aquel mundo es el que previamente tuvo que auto-configurarse de un modo determinado, y es ese modo el que Zambrano acaba asociando, vamos a ver de qué manera, a la imagen de la larva. 
La imagen de la larva es frecuente en Zambrano como saben todos sus lectores, pero aquí adquiere unas especiales connotaciones porque, entre otras cosas, esa larva, esa vida larvaria de los personajes de Kafka aparece identificada de modo explícito con la conciencia cartesiana, esa conciencia que para Zambrano es vida reducida a su mínima expresión, vida mutilada, monstruosa, vida que ha renunciado a ver, tocar, oler, gustar, oír para quedarse finalmente, tras el proceso de abstracción a que ha sido sometida, con ella misma. "Yo era una sustancia cuya esencia y naturaleza toda es pensar, y que no necesita, para ser, de lugar alguno, ni depende de cosa alguna material", escribe Descartes en la cuarta parte del Discurso del método (Descartes, 2011: 124). Esto a Zambrano, como a tantos pensadores modernos, le parece un total absurdo, un total desastre.

Lo interesante del análisis de Zambrano es, no obstante, el juego que se da entre las categorías de lo abstracto y lo concreto porque, como se sabe, la conciencia cartesiana es, en realidad, lo más abstracto que hay. Lo que hace Zambrano es buscarle una imagen a esa abstracción, a esa vida tan poco viva: la encuentra en la larva. Si se piensa bien, podría hablarse del universo de Kafka como de un universo de larvas, de vidas larvarias que caen con todo su peso muerto unas sobre otras en una amalgama informe (la sexualidad aquí tiene un peso fundamental, aunque Zambrano no se refiera a ella explícitamente), creando ese clima opresor con el que identificamos el universo de Kafka. Fiel al procedimiento de acercarse con lupa a los personajes para mostrarles en esa materialidad inerte, Haneke filmará en su adaptación a la pantalla de El castillo (1997) algunas escenas extraordinarias ${ }^{6}$.

Con la imagen de la larva Zambrano se ha referido muchas veces a la idea de ese conato de ser, de ese embrión que es para ella, en verdad, la vida del

\footnotetext{
${ }^{6}$ La cámara de Haneke, en su versión para televisión de El castillo en 1997 -a la que por cierto, denomina en los créditos iniciales fragmento en prosa y no novela incompleta-, supo captar con precisión esa descomposición o desfiguración (destrucción, diría Zambrano) de las formas. Una de las secuencias - puro expresionismo cinematográfico- más destacadas del film -fiel al relato de Kafka en su capítulo 23- es aquella, transcurrida 1 hora y 45 minutos, en que el cuerpo de $\mathrm{K}$ acaba cayendo de puro cansancio encima del secretario Bürgel, tumbado en una estrecha cama de una diminuta habitación. En el momento inercial de la caída, K desplaza la sábana que cubre a Bürgel y la cámara de Haneke entonces enfoca el dedo del pie que ha quedado al descubierto, un dedo que ya no es exactamente un dedo sino (como quizás diría Antoni Tàpies), materia en forma de dedo, lo mismo que los rostros de ambos personajes, que la cámara ha ido enfocando en primer plano de modo consecutivo a lo largo de varios minutos, pura materia abigarrada en realidad, que se confunde con el propio espacio de la habitación, mientras resuenan las palabras también inerciales del secretario y un teléfono de fondo que desde el principio de la secuencia insiste neciamente.
} 
hombre, como si en la larva latiera de algún modo aquello que más tarde verá la luz. En La tumba de Antígona, por ejemplo, la misma Antígona dice sentirse larva sin cuerpo, sin más espesor que el necesario para ser visible (Zambrano, 2012: 179), pero al final de la obra, después del descenso a los ínferos, se la ve simbólicamente renacer -ese segundo nacimiento que es para Zambrano, como para Antonin Artaud, el verdadero-. El diccionario de la RAE define larva (del larua latino) como ese animal en estado de desarrollo, que ha abandonado las cubiertas del huevo y puede ya nutrirse por sí mismo, aunque sin haber adquirido la forma y organización propia de los adultos de su especie. Así es como aparece en muchos textos de Zambrano.

Ahora bien, en los que dedica a Kafka la acepción requiere matizarse en dos sentidos convergentes. En primer término, el estado larvario no está en Kafka, entiende Zambrano, al comienzo sino al final, es decir, que lo larvario en Kafka no remite a un individuo que aún no ha desarrollado sus formas de adulto sino a un individuo que las ha perdido. Lejos de estar en proceso de con-formarse, las vidas larvarias de Kafka están en proceso de de-formarse, de des-nacer si puede decirse así, no de ir ganando cuerpo sino de ir perdiéndolo hasta quedarse convertidas en una materialidad irreconocible que apenas guarda huellas de su supuesta vida anterior ${ }^{7}$. Vidas larvarias entonces, como vidas que se han olvidado a sí mismas pero que, sobre todo, y esto es lo decisivo, que han olvidado ese olvido. A esto también se le puede llamar alienación o enajenación - ¿tal vez la oculta sede de la producción, de la que habla Marx en El Capital?-.

Dicho de otro modo: la larva representaría el enmascaramiento del propio proceso de destrucción - de transformación a menos-a que fue sometido el sujeto. Y en este aspecto merece la pena recordar que "larva" fue ya en la Antigüedad precisamente la máscara (de ahí su vínculo con el teatro). Hay una segunda acepción de la palabra que recoge asimismo el Diccionario de la RAE que apunta en esa dirección: larva como "fantasma, espectro, duende". Podría decirse entonces que las larvas de Kafka son también máscaras -máscaras larvarias, sin pensar ahora en el sentido preciso que tienen en el teatro de Jacques Lecoqque encubren, no solo el rostro que un día supuestamente fueron sino el mismo proceso de transformación a menos que sufrió ese rostro. No hablaríamos en

\footnotetext{
7 Para Walter Benjamin precisamente el olvido es una de las características decisivas de las narraciones de Kafka (Benjamin, 2009: 296), cuyos personajes carecen de toda memoria de vida anterior, de ahí esa calidad de espectros con que se presentan tantas veces - de las "espectrales tragedias del ser" habla también Zambrano en el texto de 1947-.
} 
este caso solo de estado larvario sino también larvado ${ }^{8}$, oculto, no manifestado $y$, en todo caso, de lo que hablaríamos también en ambos estados es de una monstruosidad: de la monstruosidad de la conciencia cartesiana cuando se hace realidad. Y esto es lo que las narraciones de Kafka para Zambrano vendrían a testimoniar.

Monstruo es para Zambrano el personaje, entre otros de Kafka, de Gregorio Samsa, al que asocia precisamente a la imagen de la larva9. Se dirá, con razón, que Samsa es todo menos una larva. Nos lo imaginamos con su caparazón y cavilando acerca de cómo trasladarse por la habitación -lo que, en verdad, más le preocupa, de ahí el bienestar que siente cuando observa que las patitas apoyadas en el suelo le obedecen perfectamente-. Tal vez podría decirse entonces que el hallazgo de Zambrano es haber levantado ese caparazón para observar qué hay en su interior. Y lo que encuentra ahí, en el fondo, es una vida larvaria y larvada, una monstruosidad, algo que no puede mirarse de frente, algo con lo que no puede tratarse, un resto de vida, en realidad, después del trabajo de despojamiento que ha llevado a cabo sobre ella la conciencia cartesiana, eso en que la conciencia cartesiana ha transformado la vida -como si Zambrano hubiera leído una parte del Discurso del método como la experiencia de Gregorio Samsa-.

Sabemos que a Samsa, en efecto, nadie lo puede ver, sobre todo no lo puede ver su propia familia que tanto ha contribuido, por otra parte, a su transformación pero que, al final, lo barre literalmente del suelo, después de que ya no le sostengan las patitas y se haya quedado plano y seco. Algo parecido ocurre con

\footnotetext{
${ }^{8}$ Ya en latín, larua fue, en efecto, junto al animal en fase de desarrollo, también el espectro o el fantasma, fue la palabra con que se refería el espíritu del muerto que persigue al vivo. Parece que las dos acepciones convivieron en la antigüedad, aunque la segunda se fue perdiendo hasta que, a partir del XVIII, Carlos de Linneo la recupera, considerando entonces que la larva, además de ser el animal en estado de desarrollo, contiene en-mascarado al animal adulto, una idea de en-mascaramiento que vincula a la larva con la máscara, el disfraz. Ver Dicciomed.eusal.es. Diccionario médico-biológico, histórico y etimológico, Coordinador, Francisco Cortés Gabaudan, Ediciones Universidad de Salamanca. Dirección URL: http://dicciomed. eusal.es

9 Si Gregorio Samsa se identifica con una larva es porque, como escribe Zambrano en 1941, no tiene "ni siquiera forma, no es ni tan siquiera orgánico, admite en su masa blanda, en sus tejidos corrompidos, cualquier objeto. Es solamente materia bestial, limo de la más baja animalidad, barro sin soplo creador alguno [...] Ya es de nuevo el vil gusano de la tierra, la amorfa materia inorgánica, mas sin esperanza. Desposeído de todo en su vil materia [...], opaca, corrupta, fétida, pantano de su propio ser, cieno de su entendimiento enceguecido" (Zambrano, 2013: 105-106).
} 
ese cuerpo mutilado, transformado hasta lo imposible del personaje de Johnny (Timothy Bottoms), el protagonista de Johnny cogió su fusil (1971) de Dalton Trumbo, rechazado también por la misma sociedad que lo ha creado (Vietnam y la ciencia moderna como escenarios de guerra correlativos). Lo horrible en esta película es, en verdad, lo que no se ve, lo que no puede representarse -Kafka ya advirtió, no hay que olvidarlo, que Samsa era irrepresentable ${ }^{10}-$ : ese cuerpo abandonado en manos de la ciencia, oculto tras la sábana en la cama de hospital. Lo horrible es la larva en que el ser humano se ha convertido -en que ha sido convertido, precisa Zambrano-. Eso que ni el padre, ni la madre, ni la hermana de Gregorio pueden tampoco ver, ya no la cucaracha con su caparazón sino lo que esconde esa cucaracha: la imagen de todos ellos en el espejo, su propia monstruosidad. La particularidad de Samsa, como ha escrito Reiner Stach, es que "no comprende", por eso no crece con lo que le ocurre, más bien decrece. Borges habló de "la honda trivialidad del protagonista, que contrasta con la magnitud de su perdición” (en Stach, I, 2016: 964).

La larva viene a ser, por tanto, al proceso de abstracción de la conciencia cartesiana, lo que la cifra era al proceso de abstracción de la racionalidad moderna. O dicho de otro modo: igual que la racionalidad moderna cifra el mundo, podríamos entonces decir siguiendo a Zambrano que la conciencia cartesiana larva al sujeto (al sujeto viviente, diría Zambrano) al convertirlo en "esa cosa que piensa" (2001: 131), en algo desasido, huérfano. El infierno ahora no es ya el de la maquinaria uni-forme de lo social sino el de la in-formidad de la subjetividad del hombre ${ }^{11}$. Doble proceso que corresponde al doble testimonio del que habla Zambrano.

\section{El infierno (contemporáneo) y el no-tiempo}

Utilizo la palabra infierno deliberadamente. Zambrano ha tratado del infierno en numerosos sitios, también en sus textos sobre Kafka. El infierno ha sido siempre para ella una especie de no-lugar, en tanto espacio carente de formas,

\footnotetext{
${ }^{10}$ De ahí el horror cuando una va a Praga actualmente y se encuentra a Samsa transformado (otra vez la transformación) en un souvenir.

${ }^{11}$ El 7 de abril de 1913, Kafka escribe a Felice Bauer: "lo que me proponía principalmente era librarme durante unas horas de los tormentos de que me hago objeto a mí mismo, realizar, en contraposición al fantasmal trabajo de la oficina, que se me escapa cada vez que quiero asirme a él -el verdadero infierno está allí, en la oficina, no tengo ya miedo de ningún otro-, una labor tosca, honesta, callada, solitaria, sana, esforzada" (Kafka, 1977: 353, las cursivas corresponden al subrayado del original).
} 
espacio sin límites - la conocida soledad violada de Kafka apunta en cierto modo a este espacio también sin secretos-, pero el infierno ha sido asimismo y, sobre todo, un no-tiempo. En un texto importante, Los sueños y el tiempo, Zambrano habla precisamente de esas "larvas ávidas y condenadas a pasar sin detenerse por falta de lugar; lugar que es en realidad tiempo" (Zambrano, 2006: 79). Aquí se encuentra, en verdad, la verdadera condena para Zambrano, la de la pérdida del tiempo: "perder el alma es perder el tiempo", había afirmado en Delirio y destino (Zambrano, 1998: 140).

Pues bien, tiempo es lo que han perdido radicalmente para ella los personajes de Kafka, lo que ha perdido el hombre moderno, presos todos ellos de esa particular anulación del tiempo que es la repetición. No se trata de la repetición de la variación, la vinculada a la memoria, la que hace la paz con la desaparición de las cosas, es decir, con la muerte, como apunta Walter Benjamin (1973: 318), sino la repetición incesante de lo mismo, el "desarrollo infinito de un solo minuto", como afirma Zambrano en 1947 (2001: 129). Repetición sin pasado y sin futuro, sin memoria y sin proyecto, sin salida pero también sin entrada, algo "parecido a una nada" (2001: 129), es decir, a la muerte misma ${ }^{12}$.

Por eso el viaje que emprenden los personajes de Kafka es hacia ninguna parte, porque están siempre, en realidad, en el mismo sitio, como si no pudieran despegar los pies del suelo. Kafka lo dice así hablando de K en El castillo: "aunque no se alejaba del castillo, tampoco se acercaba más a él” (Kafka, 2014: 21). Y Zambrano confirma en 1965: "K está siempre a la misma distancia del Castillo haga lo que haga” (2011: 1085). En este punto, Zambrano contraponía en 1941 el personaje de Kal de don Quijote, que nunca alcanzará a Dulcinea, es cierto, pero al menos sí se desplaza de verdad, y ello porque don Quijote cuenta precisamente con tiempo, es decir, cuenta con libertad, la única posibilidad, entiende Zambrano, de que se desarrolle el conato de ser que es siempre el hombre (2013: 106).

Si esa libertad falta, si no hay tiempo para ella, entonces más que crecimiento, lo que hay es des-crecimiento o des-nacimiento, una temporalidad a la que quizás

\footnotetext{
${ }^{12}$ En el texto de 1947 se refiere Zambrano a "un solo punto, un angosto pasillo donde los condenados se apiñan. Porque un solo punto del infierno puede desplegarse indefinidamente, desarrollarse en innumerables fugas, en largos silogismos, en interminables cadenas de deducciones y repeticiones", es un solo instante el que "desencadena el proceso sin fin. Y así es el puro presente, la actualidad sin fondo, sin ayer ni mańana. Tras de ella no aparece el misterio del pasado sosteniéndola; ni el porvenir se asoma tímidamente. No hay promesa alguna que rompa este infierno: es todo cerrado; no hay salida, y sin embargo, no hay tampoco entrada" (Zambrano, 2001:129).
} 
también podríamos llamar del después, en el sentido de Jacques Rancière en su análisis de El caballo de Turín (2011), el film de Béla Tarr, cuyos personajes no pueden tampoco levantar los pies de esa tierra llena de polvo que arrasa el viento, y que acaban protagonizando una especie de contra-génesis a lo largo de los sietes largos días en que transcurre la historia -recordemos que el film, que dura 146 minutos, se articula en torno a 30 planos secuencia-. Des-nacimiento hacia la pura nada, hacia la oscuridad de la última escena, hacia el momento de "antes de la Creación” dice Zambrano en 1941 hablando de Kafka en expresión que podría aplicarse también al film de $\operatorname{Tarr}^{13}$. Lo que queda en ese escenario, quizás, es la vida, pero ya no el mundo. Y aquí está toda la cuestión.

En relación a los personajes de El castillo, sostiene Zambrano precisamente que "son instintos de defensa los que les mantienen vivos" (Zambrano, 2011: 1083), como si la vida se hubiera reducido en ellos a ese conjunto de funciones que resisten la muerte -en definición de Claude Bernard, citada aquí por Zambrano-. También en Tarr los instintos de defensa son los únicos que actúan sobre los personajes, más muertos que vivos. Es en todos los casos -como también en los de esa otra resistencia de lo cotidiano en un mundo destruido del relato de W. G. Sebald, Sobre la historia natural de la destrucción (1999)- el tiempo del después de todas las esperas, es decir, de todos los relatos o narraciones con que se entretenía la muerte. Es el tiempo del después del mundo. Otra vez, las imágenes de los campos no están lejos -aunque en el caso de Tarr no haya que hablar del nazismo sino de la experiencia del comunismo-.

Como he dicho, el infierno -los ínferos- es un tema de reflexión habitual en Zambrano. Ahora bien, el de Kafka tiene para ella unas especiales connotaciones porque es el infierno contemporáneo, fruto de aquellas luces modernas que no quisieron saber nada de sombras y que por ello buscaron abolir la mayor de todas ellas: la del propio infierno. Craso error, dice Zambrano, porque el infierno nunca puede abolirse, está siempre ahí, amenazante, lo único que queda es encontrarle ese rostro que permita afrontarlo ${ }^{14}$. $\mathrm{Al}$ siglo $\mathrm{XX}$ le ha tocado "vivir realmente sórdidamente- el infierno que no se atrevió a contemplar", escribe Zambrano en 1947 (2001: 125). Fue la arrogancia de las luces la que quiso eliminar la pregunta por el infierno, pero el infierno regresó, y más monstruoso que nunca como regresa siempre todo lo reprimido -“sin recato alguno", dice Zambrano (2013: 101).

\footnotetext{
13 "El camino que baja desde el más alto origen fue deshecho", escribe Zambrano en ese texto (Zambrano, 2013: 106).

14 "El infierno es uno -afirma en el mismo sitio-. Y sin embargo, cada época parece tener el suyo" (2001: 124).
} 
Ese regreso monstruoso es lo que para Zambrano refleja el mundo de Kafka, y lo que encontró su expresión exacta y radical en los campos de exterminio, ese acontecimiento que, como ha explicado bien Gerard Wacjman (2001: 234), ocurrió a la vista del mundo entero, pero que el mundo entero no vio. Si recuperamos ahora la imagen de la larva y la máquina no nos resultará muy difícil asociarlas a esos campos. En este aspecto, como dije al principio del trabajo, el pensamiento de Zambrano converge con el de numerosos autores contemporáneos, entre ellos Zygmunt Bauman, quien ha sostenido que la lógica implicada en el nacionalsocialismo es una lógica moderna, que "sin ser causa suficiente del genocidio, la modernidad es su condición necesaria” (Bauman, 1991: 80). Lo que irrumpió en la Alemania de los años treinta no fue una fuerza premoderna, bárbara, irracional, sino el rostro más siniestro del proyecto moderno. De ahí que Zambrano considere que las luces fueron, en realidad, el principio de la oscuridad ${ }^{15}$.

Ahora bien, lo que también me parece interesante del análisis de Zambrano es el hecho de que vea reflejada esa lógica moderna en el mundo posterior a los campos, en la misma dirección de José Angel Valente en una entrevista de 1984, en la que Valente sostenía que "discutir si se puede o no escribir después de Auschwitz me parece anticipar las cosas. Aún no estamos después de Auschwitz" (Valente, 1984: 83) ${ }^{16}$. Es la conciencia de que la degradación de la vida (la vida dañada) ha seguido ahondándose después de la II Guerra Mundial. Fue Auschwitz e Hiroshima, pero después los procesos de descolonización (entre ellos, la guerra de Argelia), fue Vietnam, Ruanda, Etiopía, Liberia, la franja de Gaza, Irak, Siria... La persistente obsesión de las democracias occidentales de que el nazismo no regrese parte de la ficción de que después del nazismo no ha pasado nada. Esto es lo que, entre otros muchos pensadores, niega Zambrano.

Pero es que, además, para Zambrano el desastre no solo habita en esos espacios de destrucción sino en lo profundo de las democracias occidentales, fundadas, entre otras cosas, en su propia buena conciencia cada vez que legislan

\footnotetext{
15 "El avance -escribe Zambrano en 1941- ha resultado un retroceso y nos encontramos en el mismo lugar de donde habíamos partido, mas ya en la miseria más atroz" (2013: 105), una miseria que nos habla de la imposibilidad de vivir y, más aún, paradójicamente de la imposibilidad de morir (2013: 106). Lo sabemos: en los campos no se moría porque allí no había vida, en los campos se fabricaban muertos, que no es lo mismo, muertos que luego se olvidaban, se eliminaban como residuos. La reflexión de Zambrano es de 1941, cuando las noticias sobre los campos no son aún las más atroces. En 1965 se referirá a esa muerte no-muerte con la palabra "aniquilación” (2011:1082).

16 "Auschwitz ya existía antes. Auschwitz se ha seguido reproduciendo después en otros lugares”, escribe también Valente.
} 
(y es lo que sobre todo saben hacer) supuestamente a favor de las víctimas. No nos enseñaron a desconfiar de los buenos, ha escrito Chantal Maillard en su último libro de poemas, La herida en la lengua (2015). Zambrano entendió que no hace falta imaginar escenarios clásicos de guerra para enfrentarse al desastre. En este aspecto, una película como La cuestión humana (2007) de Nicolas Klotz propone claves definitivas. Lo mismo que, más dura si cabe, la noruega El inadaptado (2006) de Jens Lien. Creo que a Zambrano le hubieran interesado especialmente, porque el infierno de Kafka es para ella también el de esas vidas cotidianas de millones de individuos en las sociedades occidentales, ajenos al desastre diario de su propia alienación, a nuestro propio desastre diario. La máquina, en ese contexto, ya no sería tanto reflejo de un mundo superorganizado sino de "las costumbres y los usos", como escribió Günter Anders (2007: 89), muy cercano también en esta ocasión a Zambrano.

No debe sorprendernos que Haneke, el director de El séptimo continente (1989) o de Funny games (1997), seleccionara El castillo (1997) para su adaptación a la pantalla. $\mathrm{K}$ es aquel que no escoge ya sus aventuras pero que no lo sabe. $\mathrm{K}$ no reclama ya imaginación ("píntola [a Dulcinea] en mi imaginación como deseo", se defendía don Quijote) sino derechos. El fin es entrar en una comunidad institucionalizada, esfuerzo vano porque $\mathrm{K}$, como auténtico extranjero, permanecerá siempre afuera aunque no lo sepa ${ }^{17}$. K es y será siempre habitante de esa nieve que cruje al pisarse, y que tanto se parece -Haneke nos lo hace terriblemente visible- a un cielo caído, a una nada -sin hierogamia alguna, pura caída-.

La palabra nihilismo es frecuente en los textos de Zambrano y aparece asociada muchas veces de modo significativo a la palabra humanismo ${ }^{18}$. Hay en este aspecto en Zambrano conciencia, nada nostálgica, del agotamiento de una tradición, la de la modernidad, en la que el hombre ocupó un lugar central, ese hombre identificado con el sujeto soberano. Estamos cansados de el hombre, podría haber dicho con el Nietzsche de La genealogía de la moral. Ese hombre que quizás esté todavía vivo pero que carece de mundo, lo ha abs-traído, arrancado de raíz ${ }^{19}$.

\footnotetext{
${ }^{17}$ Los personajes de Samuel Beckett -de quien nunca habló, hasta donde se me alcanza, Zambrano- representan una vuelta de tuerca más, se les ha olvidado incluso querer entrar en el castillo del mundo, como vio también Günter Anders, y por ello ni siquiera son capaces de vivir su propio nihilismo (Anders, 2011: 213 y 215).

${ }^{18}$ En los textos sobre Kafka, Zambrano habla de que una "justicia nihilista arrasa el mundo", de la "absoluta y ciega, sorda sumisión nihilista" (Zambrano, 2013: 110).

${ }^{19}$ En Filosofía y poesía (1939) se había referido Zambrano a ese "género de mirada que ha dejado de ver las cosas" refiriéndose a la abstracción moderna del pensamiento (Zambrano,
} 


\section{Conclusiones}

En resumen, lo que Kafka aportaría entonces para Zambrano es una desilusión, la que habla de que el hombre pueda, en verdad, sostenerse solo en un mundo que ya no existe, en un mundo transformado en una "vacía abstracción" que, eso sí, necesita siempre "algo vivo con que alimentarse. Y no lo encuentra porque todo lo que toca lo mata" (Zambrano, 2013: 110). El diagnóstico es bastante desolador, apunta a esa modernidad, a ese círculo de la economía donde el capital es el protagonista, un capital que tiene tanto que ver con la máquina de producción como con la larva in-forme, en tanto el capital es aquello que adopta cualquier forma sin jamás fundar nada. El capital es lo de-constituyente por excelencia, olvida todo el rato lo representado en favor de la representación y, sobre todo, oculta ese olvido. En todo caso, lo único que funda o constituye el capital es el hambre: "el hambre de los que no comen y el hambre mucho mayor de los que no dejan de comer" (Alba, 2007: 36). Lo abstracto y lo concreto en el sentido que aquí los hemos tratado acompañan también al capital, ese que no vemos pero nos toca todo el rato, como la ley de Kafka. Ahí sigue habiendo vida, lo que ya no hay es mundo. Y la vida sin mundo es invivible. Es el infierno. Esta es la precisa denuncia de Zambrano en convergencia, por los mismos años, con un autor como Günter Anders, que se atrevió a hablar de la obsolescencia del hombre en este escenario.

Hacia 1960, el ensayista argentino, Ezequiel Martínez Estrada, escribía las siguientes palabras: "Llamo apocalipsis (revelación de lo que está oculto -por medio de símbolos-) a la obra de Franz Kafka [...] El mundo que nos revela es el que habitamos pero no el que vemos" (Martínez Estrada, 2013: 195). Son palabras muy cercanas a las de Zambrano en los tres textos sobre Kafka que pueden sintetizar la respuesta a la pregunta que me hacía al principio de este trabajo: ¿por qué la relevancia de Kafka en Zambrano? Pues precisamente porque Kafka hace visible lo que no vemos, da a ver eso que, en realidad, es un irrepresentable. Zambrano lo dice así: Kafka ha sido capaz de "revelar el submundo, poniéndolo a la luz" (Zambrano, 2001: 129). Y en esto Kafka ha sido para Zambrano, esto me parece fundamental por lo que respecta a un apunte de futuro, un "profeta".

A M. M., por sus clases de filosofía.

1987: 15). Y en 1933, en "Nostalgia de la tierra", había lamentado también que se hubiera perdido la tierra, "camino adentro de la conciencia -terrible devoradora de realidades-" (Zambrano, 1991: 15). 


\section{Bibliografía}

Alba, Santiago (2007). Capitalismo y nihilismo, Madrid, Akal.

Anders, Günter (2007). Hombre sin mundo, Valencia, Pre-Textos.

- (2011). La obsolescencia del hombre (Vol. I), Valencia, Pre-Textos.

Bauman, Zygmunt (1991). Modernidad y ambivalencia, Barcelona, Anthropos.

Benjamin, Walter (1973). “El narrador”, Revista de Occidente, 129, pp. 301-333.

- (2009). "Franz Kafka: 'Construyendo la muralla china”, en Obras, libro II/ vol. 2, ed. R. Tiedemann y H. Schweppenhäuser, ed. española, J. Barja, F. Duque, F. Guerrero, Madrid, Abada, pp. 290-297.

Blumenberg, Hans (2003). Paradigmas para una metaforología, Madrid, Trotta.

Descartes, René (2011). El discurso del método, en Descartes, Estudio introductorio Cirilo Flórez Miguel, "René Descartes, la constitución de la modernidad", Madrid, Gredos.

Kafka, Franz (1977). Cartas a Felice (II) 1913, Madrid, Alianza Editorial.

- (2014). El castillo, Madrid, Alianza Editorial.

Llevadot, Laura (2010). "Para una crítica de la novela: Zambrano y Benjamin”, Aurora, 11, pp. 77-87.

Martínez estrada, Ezequiel (2013). "Intento de señalar los bordes del mundo de Kafka" (1944), "Acepción literal del mito en Kafka” (1950) y "Apocalipsis de Kafka” (1960), en Martínez Salazar, Elisa y Yelin, Julieta (selección, edición e introducción), Kafka en las dos orillas. Antología de la recepción critica española e hispanoamericana, Zaragoza, Prensas de la Universidad de Zaragoza, 2013, pp. 112-118, 176-182 y $195-199$.

Pardo, Carmen (2003). "La materia del logos", Aurora, 5, pp. 95-100.

SEMPrún, Jorge (1995). La escritura o la vida, Barcelona, Tusquets.

Stach, Reiner (2016). Kafka, 2 vols. Barcelona, Acantilado.

Valente, José Angel (1984). Entrevista J. Martín Arancibia, Quimera, 39-40, pp. 83-86.

Wacjman, Gerard (2001). El objeto del siglo, Buenos Aires, Amorrortu Editores.

Zambrano, María (1987). Filosofía y poesía, Madrid, Fondo de Cultura Económica.

— (1991). "Nostalgia de la tierra" (1933), en Algunos lugares de la pintura, recopilación Amalia Iglesias, Madrid, Espasa Calpe, pp. 15-22. 
- (1998). Delirio y destino: los veinte años de una española, edición completa y revisada por Rogelio Blanco y Jesús Moreno Sanz, Madrid, Centro de Estudios Ramón Areces.

- (2001). "Franz Kafka, un mártir de la lucidez”, Asomante (Puerto Rico), 1, eneromarzo 1947, pp. 5-17. Edición utilizada aquí, Aurora, 3, pp. 124-132.

- (2006). Los sueños y el tiempo, Madrid, Siruela.

- (2011). "La novela-tragedia: El castillo, de Kafka”, El sueño creador, México, Universidad Veracruzana, 1965, pp. 87-103. Edición utilizada aquí, El sueño creador en Obras completas, III, Jesús Moreno Sanz, Galaxia Gutenberg / Círculo de Lectores, pp. 1079-1087.

- (2012). La tumba de Antígona y otros textos sobre el personaje trágico, ed. Virginia Trueba Mira, Madrid, Cátedra.

- (2013). “Franz Kafka, mártir de la miseria humana”, Espuela de Plata (La Habana), agosto de 1941, pp. 3-8. Edición utilizada aquí, Kafka en las dos orillas, E. Martínez Salazar y J. Yelin, pp. 101-111.

Recibido: 1/02/2018

Aceptado: 9/03/2018

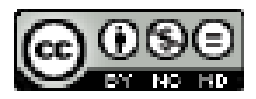

ENDOXA está bajo una licencia de Creative Commons Reconocimiento-NoComercial-SinObraDerivada 4.0 Internacional 
